\title{
Nas trincheirras do método: 0 ensino da metodologia das ciências sociais no Brasil
}

IGNAGIO GANO"

\section{Resumo}

O artigo reflete sobre o ensino tradicional das ciências sociais no Brasil a partir do seguinte diagnóstico inicial: uma ênfase excessiva nos clássicos e na erudição em detrimento da pesquisa empírica. Em segundo lugar, pretende analisar o ensino da metodologia das ciências sociais no país, permeado por uma falsa oposição entre as técnicas quantitativas e qualitativas, que são elevadas à categoria de metodologias diferentes e inclusive contraditórias. Esta guerra metodológica salda-se, com frequência, com a derrota do suposto 'método quantitativo', ao qual são associados defeitos epistemológicos de raiz e, inclusive, conteúdos ideológicos. Neste contexto, o termo 'positivista' costuma ser usado mais como insulto metodológico do que como descrição de uma corrente epistemológica real. A visão metodológica triunfante tende a ver a pesquisa mais como uma arte do que como um empreendimento sujeito a critérios de validação objetivos e rigorosos. Este cenário provoca que outros profissionais, como os economistas e os estatísticos, acabem ocupando, na prática, o espaço abandonado pelos cientistas sociais.

Palavras-chave: Métodos em ciências sociais. Técnicas quantitativas e qualitativas. Ensino de metodologia.

\footnotetext{
* Doutor em Sociologia. Professor Adjunto da Universidade do Estado do Rio de Janeiro (Brasil).E-mail: ignaciocano62@gmail.com
} 


\section{In the trenches of method: the teaching of methodology in social sciences in Brazil}

\section{Abstract}

This paper reflects on the traditional teaching of social sciences in Brazil based on a previous diagnosis of its excessive focus on classical sociology and on scholarship to the detriment of empirical research. Second, we seek to analyze the teaching of social sciences methodology in the country, which is permeated by a false opposition between quantitative and qualitative techniques. These latter, further, are raised to the status of different, and even conflicting, methods. Such methodological war is often ended by the defeat of the supposed 'quantitative method' to which epistemological problems of origin and even ideological contents are associated. In this context, the term 'positivist' is typically used as a kind of methodological insult, rather than referring to an actual epistemological theory. For the winner methodological perspective research would be rather an art than an enterprise subjected to objective and strict validity criteria. Such a context allows that other professionals as economists and statisticians come to occupy, in practice, the space neglected by social scientists.

Keywords: Methods in social sciences. Quantitative and qualitative techniques. Teaching of methodology.

\section{O nascimento das ciências sociais e a sua metodologia}

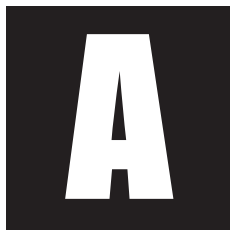

s ciências sociais nasceram no século XIX como uma tentativa de compreender e controlar uma realidade social cada vez mais complexa, que tinha mudado de forma dramática nos últimos séculos, como consequência de transformações na tecnologia, nas formas de produção econômica e nas relações sociais. Após séculos de relativa estabilidade durante a Idade Média, a Europa havia experimentado revoluções tecnológicas, econômicas e políticas que geravam grandes esperanças, mas também enorme mal-estar. Emergiram novos problemas sociais e tam- 
bém propostas conflitantes sobre como organizar a sociedade. O avanço da ciência gerava uma erosão progressiva da cosmovisão tradicional, das certezas sobre o universo, o próprio homem e o seu papel no mundo. A ciência tinha diminuído também o poder físico e simbólico das autoridades religiosas, relegando a religião cada vez mais à esfera privada. Nos embates entre o saber sagrado e o conhecimento científico, este último emergia como hegemônico, alavancado no seu enraizamento na realidade empírica, na sua universalidade e, sobretudo, na legitimidade que the outorgava a sua paternidade sobre as mudanças tecnológicas. Do ponto de vista político, a ciência, como um saber impessoal baseado em evidências empíricas e não mais na legitimidade da fonte do saber, estava em consonância com os ideais igualitários da Ilustração.

As ciências sociais foram, em suma, filhas da perplexidade perante um mundo em vertiginosa transformação. Os seres humanos, como adolescentes que se olham no espelho sem se reconhecerem no passado e incertos quanto ao futuro, estavam à procura de um saber que permitisse entender o presente e orientar a ação social e política futura.

Nesse cenário histórico, nada parecia mais razoável do que aplicar ao estudo da sociedade as mesmas ferramentas que tinham se revelado tão exitosas no controle da natureza. Por isso, o positivismo liderado por Auguste Comte propôs adotar, nas ciências sociais, o mesmo método das ciências naturais. De fato, Comte é considerado, na tradição ocidental, o pai da sociologia moderna, embora outras matrizes culturais reclamem outras figuras pioneiras, como Ibn Khaldun (Ibn Khaldun, 1977) nos países árabes.

O positivismo, do ponto de vista metodológico, pode ser resumido em três princípios: a) o monismo metodológico, isto é, a crença num único método para todas as ciências, seja qual for o objeto de cada uma delas; b) a aplicação do método das ciências naturais, baseado na matemática, às ciências sociais; e c) a busca de leis e de explicações causais como objetivos centrais de qualquer ciência. 
Contra esta visão positivista levantaram-se diversas vozes da filosofia e da historiografia alemã para reivindicar a especificidade das ciências sociais. Wilhelm Dilthey distinguiu as Geisteswissenschaften (Ciências do Espírito, que poderiam incluir à época, entre outras, a psicologia, a sociologia, a história e a filologia) das ciências da natureza (Naturwissenschaften), reivindicando uma epistemologia e uma metodologia próprias para as primeiras. Por sua vez, Wilhelm Windelband introduziu os conceitos de ' $\mathrm{Ci}$ ências Nomotéticas', preocupadas com a formulação de leis e princípios gerais (que explicariam os casos individuais apenas de forma dedutiva), e 'Ciências Ideográficas', que teriam como objetivo a descrição detalhada e a compreensão de fenômenos individuais e únicos, como seria o caso da história. Heinrich Rickert escreveu um livro intitulado "Kulturwissenschaft und Naturwissenschaft" que contrapunha as 'Ciências da Cultura', termo que se tornaria muito caro para Max Weber, às da natureza.

Embora as fronteiras entre as diversas ciências fossem flexíveis ao longo desse percurso, inclusive porque muitas delas estavam ainda em processo de consolidação, o ponto comum a todas estas formulações era a rejeição de uma ciência social pautada exclusivamente nos moldes da ciência natural. Com o tempo, estas discussões epistemológicas cristalizaram-se nos dois grandes paradigmas da ciência social: a Compreensão (Verstehen, na sua formulação alemã) versus a Explicação (Erklären).

Enquanto a Explicação visava à identificação de leis do comportamento humano e à determinação das causas da conduta e, nesse sentido, era paralela às ciências da natureza e condizente com os postulados do positivismo, a Verstehen procurava encontrar o sentido da ação social. A noção de sentido poderia ser traduzida como o significado que os atores sociais atribuem à sua própria conduta, aproximando-se assim do conceito de 'motivo'.

Note-se que 'sentido' também pode ser entendido como função para um grupo social. Este era o caso, por exemplo, da visão organicista, muito popular nos inícios da sociologia, que concebia a sociedade como 
um organismo vivo, ou seja, como um sistema único para cujo funcionamento era necessária a integração de todas as células (indivíduos, grupos) que o compunham. Embora a noção de 'função' seja alheia à matriz cultural da Verstehen, alguns autores incluem tanto os organicistas quanto os que procuram o significado da ação dentro de uma mesma perspectiva teleológica (ver Von Wright, 1971), em qualquer caso oposta à consideração da ciência como simples busca de leis e causas.

Seja qual for a maneira de entender o conceito, não resta dúvida de que ele é próprio das ciências sociais, pois não faria sentido que o astrônomo ou o químico se questionassem pelo sentido atribuído ao comportamento dos objetos que estudam. As órbitas dos planetas ou as reações químicas não possuem sentido, simplesmente acontecem com certa regularidade, que o cientista deve constatar e descrever.

Nas Ciências Sociais, entretanto, a coincidência entre o sujeito que estuda e o objeto de estudo abre um mundo de possibilidades, entre elas a de que o cientista se interrogue a si mesmo, enquanto membro de um grupo, sobre o significado das ações dos indivíduos desse grupo, através da introspecção ou da empatia. Outro elemento de grande relevância é que o produto do conhecimento das ciências sociais pode transformar o seu objeto, pois os seres humanos podem usar esse saber para mudar o seu comportamento.

Max Weber é classificado dentro da Sociologia da Verstehen; entretanto a sua posição no debate epistemológico pode ser considerada como integradora. Para o sociólogo alemão, o objetivo da ciência social deve contemplar a busca de leis - embora elas sejam aqui de utilidade limitada ${ }^{1}$ - e, sobretudo, as causas das condutas, mas não pode se limitar a elas. Para ser fiel ao seu destino, a ciência social precisa encontrar o

\footnotetext{
${ }^{1}$ Max Weber afirma que enquanto nas ciências da natureza as leis são tanto mais valiosas quanto mais gerais, no mundo social as leis mais gerais acabam sendo as mais vazias de conteúdo (Weber, 1979).
} 
sentido que os indivíduos atribuem a suas ações. Ou seja, a verdadeira ciência social deve partilhar o caminho da Explicação com as outras ciências, mas deve também se aventurar num percurso solitário em busca da Compreensão (Verstehen).

Por sua vez, Weber (1979) explica que o sentido da conduta só pode ser compreendido em função dos valores em que ela se inscreve. Sem compartilhar, em alguma medida, o mundo valorativo do ator, sem conhecer suas crenças, atitudes, conhecimentos, sua Weltanschauung (cosmovisão) em suma, o seu comportamento nos é ininteligível. Quando lemos que uma pessoa matou o seu parceiro por ciúmes, entendemos essa conduta não porque ela seja racional (em termos do emprego de meios adequados à consecução de fins) ou porque estejamos de acordo com ela, mas apenas porque o motivo da ação (o ciúme e a raiva que comporta) faz sentido no nosso mundo, talvez porque conheçamos alguém que já cometeu algum ato agressivo por causa do ciúme ou até porque nós mesmos sentimos alguma vez a força corrosiva de tal sentimento. Dessa forma, os valores são transformados de um elemento de risco para o cientista, na medida em que podem enviesar o seu afazer profissional, em uma ferramenta essencial para a compreensão do seu objeto. Essa revolução copernicana na abordagem dos valores é central para a noção de Ciências da Cultura weberiana. Contudo, o emprego dos valores não significa que a ciência social não possa aspirar, como toda ciência, à objetividade no tratamento do seu objeto. Se os 'juízos de valor' possuem plena legitimidade na eleição daquilo que será estudado, a sua influência na determinação da maneira de pesquisar e na validade das conclusões deve ser contida, sob risco de perder a aspiração à universalidade que caracteriza todo o trabalho científico. Em outras palavras, a eleição do objeto que será estudado, como a das prioridades de financiamento para agências de pesquisa, é um juízo de valor fundamentado em critérios 
políticos ou culturais. Já a forma em que o estudo será conduzido deve responder a critérios objetivos de validação e não pode ficar apenas a mercê de valores culturais.

De fato, a ciência se caracteriza mais pelas formas do que pelo conteúdo, que é sempre provisório e sujeito a revisão. Na dicotomia epistemológica clássica entre o 'Contexto de Descoberta', que tem a ver com a gênese de novas hipóteses e teorias, e o 'Contexto de Justificação', relacionado com o teste empírico de tais hipóteses e teorias, a ciência se distingue pela prevalência do segundo sobre o primeiro. Em outras palavras, independentemente de onde venha uma teoria, o que lhe conferirá ou retirará legitimidade científica não é a sua origem, quem ou como a formulou, mas a forma como ela é validada empiricamente. É justamente a metodologia que se apresenta como o guardião desta validação. Assim, os livros de metodologia dizem muito pouco sobre como gerar novas teorias, mas dão muitos detalhes dos procedimentos para testá-las ou falsificá-las. De certa forma, a metodologia pode ser entendida como um 'Superego' (Gigerenzer, 1993) cuja missão é exercer um controle férreo sobre o ld do conhecimento comum, sempre inclinado a diversos vieses autoconfirmatórios.

\section{Abordagens quantitativas e qualitativas}

Embora o binômio 'Explicação versus Compreensão' seja conceitualmente diferente da comparação entre diversos tipos de metodologias, historicamente a busca pelas causas esteve mais associada a técnicas de pesquisa quantitativas, enquanto que o estudo do sentido da ação foi abordado, sobretudo, com técnicas qualitativas. Observe-se que isto não é uma necessidade lógica, apenas uma tendência histórica. Há, por exemplo, pesquisas que tentam entender os sistemas de valores das sociedades, indispensáveis para pensar os sentidos da conduta, a partir de 
surveys realizados a amostras representativas das respectivas populações (Inglehart et al., 2004; Schwartz, 1990). Por outro lado, nada impede que o estudo das causas seja abordado com técnicas qualitativas. De qualquer forma, a tradição da Verstehen tem usado prioritariamente pesquisas qualitativas, e o contrário poderia ser dito dos que possuem uma visão mais centrada em leis e causas.

Mesmo que diversos autores próximos das ciências sociais, como Quetelet, já tivessem usado estatísticas oficiais, não resta dúvida de que 'O Suicídio' de Durkheim, publicado em 1897, é percebido como o primeiro clássico da sociologia a fazer uso extensivo de dados quantitativos. A tentativa de encontrar regularidades nas taxas de suicídios e de explicar tanto as invariâncias quanto as diferenças (dentro de cada nação e entre os diversos países), através das características de cada sociedade e das conjunturas históricas, representou uma contribuição revolucionária.

Por sua vez, a antropologia vivia, em princípios do século $X X$, a sua consolidação como disciplina, em oposição à velha etnologia centrada na interpretação, no gabinete, de objetos folclóricos trazidos por viajantes e missioneiros. A partir das contribuições de Franz Boas e, especialmente, da publicação de Os Argonautas do Pacífico Ocidental de Bronislaw Malinowski, em 1922, a antropologia se identifica com a etnografia: a análise das culturas nativas, através de um processo de imersão prolongada no grupo, que permita entender a conduta, a subjetividade e o discurso daqueles que se pretende estudar. A técnica de pesquisa por antonomásia é a observação participante, para muitos quase um sinônimo do 'Trabalho de Campo', que pretende entender a cultura estudada através da empatia e da experimentação das mesmas condições de vida. Malinowski, ele próprio originariamente doutor em física e matemática pela Universidade de Cracóvia, fala num "método de documentação estatística por evidência concreta", mas o seu legado é hoje mais associado com as anotações qualitativas num caderno de campo. 
O velho positivismo, que cumpriu um papel essencial na criação da noção mesma da ciência social, foi, como já vimos, arduamente contestado na Alemanha da segunda metade do século XIX e teve um papel decrescente nas ciências sociais do século XX. Contudo, nos anos 20 e 30, um grupo de filósofos do Círculo de Viena reformulou os princípios positivistas no que foi denominado Positivismo Lógico ou Empirismo Lógico. Estimulados por figuras como Bertrand Russell e Ludwig Wittgenstein, os neopositivistas rejeitaram a metafísica e com ela todos os princípios não observáveis, incluindo a noção de causa, optando por definições operativas e relações funcionais entre os fenômenos como as que se podem encontrar nas equações da física fundamental $\left(E=m C^{2}\right)$. Os neopositivistas influenciaram a filosofia ocidental, e particularmente a Filosofia da Ciência, durante alguns anos, após a sua saída de Áustria com a chegada do nazismo. Em psicologia, o behaviorismo, que rejeita todos os conceitos não observáveis, entre eles o da 'consciência', pode ser considerado um herdeiro direto destas ideias. Entretanto, a sua influência na prática dos cientistas sociais foi bem mais limitada. No momento atual, não há uma escola de cientistas sociais que se defina como positivista, embora o termo continue sendo usado, como será mostrado mais adiante, de forma pejorativa.

Um momento significativo na consolidação metodológica das ciências sociais é a chamada 'Escola de Chicago', que produziu estudos pioneiros nas três primeiras décadas do século $X X$, e continuou tendo uma influência destacada até meados do século. A Escola de Chicago se caracterizou pelo seu foco no território, através de uma visão ecológica que tentava entender, e ajudar a resolver, os problemas associados a sua própria cidade. Do ponto de vista teórico, a influência mais relevante foi a do interacionismo simbólico de George Herbert Mead. Do ponto de vista metodológico, ela é tradicionalmente associada às pesquisas qualitativas, mas produziu muitos estudos quantitativos e ainda outros 
que compatibilizavam técnicas diversas. O estudo clássico de Thomas e Znaniecki O Camponês Polonês na Europa e na América, publicado em cinco volumes entre 1918 e 1920, utilizava uma variedade de fontes e técnicas, entre elas: artigos de jornais, arquivos oficiais, cartas trocadas entre migrantes poloneses nos EUA e suas famílias do outro lado do Atlântico, e um longo relato autobiográfico de um migrante. De fato, a tradição de estudar um grupo social através da coleta de relatos autobiográficos dos seus membros, solicitados com este propósito, fez um grande sucesso nas ciências sociais polonesas durante décadas. Por outro lado, este trabalho teve grande importância no surgimento da história de vida como uma ferramenta de pesquisa social, analisando o percurso biográfico de um indivíduo através da sua própria visão. A Escola de Chicago dedicou atenção especial às histórias de vida de indivíduos desviantes, como The Jack-Roller: A delinquent's boy own story, publicada por Clifford Shaw em 1930. Assim, se essa Escola desempenhou um papel importante na difusão de técnicas qualitativas na sociologia, para além do seu uso na antropologia que estava sendo consolidado pela etnografia, ela também estimulou a realização de pesquisas quantitativas, como o estudo de Stouffer, The American Soldier. Publicado em 1949, esse trabalho tentava mensurar as atitudes dos soldados através de entrevistas e de questionários. Em criminologia, Chicago é, inclusive, considerada um centro pioneiro na coleta e análise de estatísticas criminais.

A consolidação do uso de diversas técnicas de pesquisa acontece também em diálogo com outras disciplinas. Nos anos 20 do século passado, o jornalista Walter Lippmann (1922) publica um volume pioneiro dos estudos sobre opinião pública, que cita tanto pesquisas com questionários aplicados a uma amostra de pessoas, quanto experimentos psicológicos de corte cognitivo e inclusive argumentos de base filosófica.

Após a Segunda Guerra Mundial, a hegemonia política e econômica dos Estados Unidos se expandiu também ao mundo acadêmico. Nas Ci- 
ências Sociais norte-americanas, que tinham experimentado um grande crescimento durante o conflito bélico, as técnicas quantitativas saíram reforçadas. Na Sociologia, e especialmente na Ciência Política, o ensino de métodos quantitativos passou a ser padrão.

Em alguns casos, houve excessos, como a mensuração extensiva de opiniões através de surveys, sem que houvesse necessariamente uma hipótese ou uma teoria que explicasse qual seria o objetivo de tal mensuração. Esta mensuração pelo prazer de mensurar foi denominada pejorativamente de 'empiricismo'. Entretanto, a tendência a mensurar sem teoria e sua correspondente empolgação fetichista com o método foram perdendo progressivamente fôlego, na medida em que ficava evidente a inutilidade de parte dos dados coletados.

Como contraposição à expansão das pesquisas quantitativas, começaram a surgir, nos EUA e em outros países, tanto dentro das ciências sociais quanto de outras ciências afins (educação, psicologia, etc.), opositores às técnicas quantitativas e à cosmovisão que, segundo eles, as inspirava (Lincoln; Guba, 1985). O alvo de todas as críticas era um 'positivismo' difuso e mal definido, que encarnava todos os males atribuídos ao quantitativismo. Em alguns casos, havia também uma crítica política sustentando que esse 'positivismo' era aliado de posições conservadoras, às quais cabia opor filosofias libertadoras: feminismo, valorização das minorias étnicas, defesa e conscientização do proletariado, etc. No seu radicalismo antiquantitativo, algumas dessas posições acabavam, explícita ou (mais comumente) implicitamente, embarcando num relativismo absoluto do conhecimento, oposto à noção mesma de ciência. Na área de avaliação de programas sociais, por exemplo, a ideia de que o resultado da avaliação precisava ser elaborado em conjunto com os grupos afetados levava, no extremo, à renúncia completa a qualquer pretensão de objetividade.

De qualquer modo, independentemente de excessos ocasionais em qualquer direção, a ciência social ao longo do século XX caminhou na dire- 
ção de um consenso sobre a especificidade do seu objeto, no sentido weberiano, como uma disciplina que não podia ser idêntica às ciências naturais, pois precisava se preocupar com o sentido e a percepção dos atores. O uso de métodos qualitativos, junto aos quantitativos, fez parte deste consenso.

Por outro lado, é inegável que, historicamente, houve alguma decepção na ciência social com o seu próprio desempenho. O grau de universalidade e de cumulatividade do conhecimento social é indubitavelmente inferior ao atingido pelas ciências exatas ou naturais. Poder-se-ia dizer que esta constatação gerou um mal-estar nas ciências sociais. Ele foi mais acentuado após os dois momentos históricos de otimismo quanto ao papel histórico da ciência social. O primeiro corresponde justamente ao positivismo inicial, quando se esperava que a ciência social trouxesse, para a sociedade, avanços comparáveis aos obtidos pela ciência natural na transformação do mundo, e Auguste Comte conseguia sonhar com um mundo regido pelos sociólogos na sua qualidade de especialistas no comportamento humano. O segundo grande momento, embora menos intenso, foi o imediatamente posterior à Segunda Guerra Mundial, quando os avanços metodológicos experimentados ao serviço do esforço bélico abriram expectativas de uma evolução rápida do conhecimento científico-social que se traduzisse numa melhora do bem-estar. As expectativas, nesses dois momentos históricos, foram muito além das realizações efetivas.

Obviamente, parte dessa frustração parece ser atribuível ao próprio objeto da ciência social, aparentemente mais mutável e menos inclinado a regularidades do que o das ciências naturais. Homens parecem claramente mais imprevisíveis do que animais ou minerais. Por outro lado, como já foi observado, o princípio de que o próprio saber social possa mudar o seu objeto, isto é, a conduta, introduz numerosas complicações.

O que não está tão claro é em que medida os próprios cientistas são responsáveis por este cenário. Alguns se manifestaram satisfeitos, na medida em que renunciam à ciência social como um conhecimento está- 
vel no tempo ou necessariamente cumulativo. Mas isto não acabou com o mal-estar da maioria. Para tentar explicar esta situação, Ritzer (1975) descreveu a sociologia como multiparadigmática, ou seja, uma ciência na qual convivem, ao mesmo tempo, abordagens teóricas e metodológicas muito diferentes e até confrontadas entre si. Observe-se que a ideia de mudança de paradigmas, isto é, revoluções na forma de fazer ciência, não era nova e tinha surgido a propósito das ciências naturais (Kuhn, 1962). A diferença aqui é que os paradigmas nas ciências sociais não se sucediam um a outro de forma diacrônica, mas conviviam sincronicamente.

Neste sentido, Kaplan (1964) afirma que a multiplicidade de escolas não é exclusiva das ciências sociais (pensemos na geometria euclidiana e não euclidiana ou na estatística frequentista versus a bayesiana). O nosso diferencial, no entanto, seria a hostilidade extrema entre as diversas escolas. Em relação a este mal-estar metodológico, um conceito relevante apresentado pelo próprio Abraham Kaplan (1964) é o que ele denomina 'Mito da Metodologia'. Este consistiria na crença de que as dificuldades mais sérias enfrentadas pelas ciências da conduta são basicamente metodológicas, de forma que, se fosse possível 'acertar' a metodologia, o progresso estaria garantido. Em contraposição a esta visão mítica, Kaplan (1964) afirma que o método não é condição necessária nem suficiente para uma ciência bem sucedida. O próprio Weber já tinha sustentado que acreditar que a reflexão sobre os próprios métodos é uma precondição necessária para o trabalho intelectual equivaleria a pensar que o conhecimento de anatomia fosse indispensável para poder andar corretamente.

Paradoxalmente, nenhuma outra ciência dedica tanto esforço e cavilação a pensar no seu método. Nas faculdades de ciências naturais, por exemplo, não costumam existir disciplinas específicas sobre método. Ele é absorvido de forma implícita ao tempo que se estudam os conteúdos. É justamente o espírito atormentado das ciências sociais e a luta entre 
escolas ou paradigmas rivais que têm alimentado o interesse no método e intensificado as disputas em torno dele.

\section{Métodos e Técnicas}

Os termos métodos e técnicas de pesquisa são usados geralmente de forma equivalente, embora existam diferenças entre ambos. Métodos seriam estratégias de produção de conhecimento científico, incluindo a geração e a validação de teorias. Técnicas seriam formas padronizadas de coleta e análise de dados, com a mesma finalidade, a de produzir conhecimento válido. Embora a diferença entre os dois conceitos seja porosa, o método é muito mais abrangente e se aproxima da epistemologia, contemplando estratégias gerais, enquanto que a técnica é específica e concreta. Para Kaplan (1964), métodos seriam 'técnicas de alcance intermediário', suficientemente gerais para serem comuns a todas as ciências ou a uma parte significativa delas. O termo também poderia ser aplicado a princípios lógicos ou filosóficos suficientemente específicos para diferenciar a atividade científica de outros propósitos ou interesses.

Métodos clássicos seriam o Método Indutivo e o Dedutivo. Exemplos de técnicas seriam a aplicação de questionários a uma amostra da população (o survey), a observação participante, o grupo focal e a entrevista em profundidade. Não raro, muitos autores defendem o status de método para o que os outros consideram uma técnica, como acontece com o Estudo de Caso, a História de Vida ou a Etnografia.

De qualquer forma, é preciso dizer que o Método Quantitativo e o Método Qualitativo, a rigor, não existem, por mais que os termos sejam usados à exaustão. A quantificação ou não das mensurações é um aspecto exteriormente muito visível, mas secundário do ponto de vista epistemológico. Com efeito, não há nenhuma estratégia profunda de geração de 
conhecimento válido que parta do fato do dado ser numérico ou não. Assim, embora o conhecimento ou desconhecimento da ferramenta da estatística possa representar uma diferenciação entre os cientistas sociais, os dilemas epistemológicos centrais enfrentados são comuns para o etnógrafo e para o profissional que trabalha com surveys. A observação e o registro do comportamento humano, o problema das fontes, os vieses de apresentação pública das pessoas e os introduzidos pelo próprio pesquisador, o teste das hipóteses iniciais sem se deixar levar pela tentação autoconfirmatória, a interpretação de evidências ambíguas, o surgimento de questões de pesquisa que não tinham sido previstas, entre muitos outros, são problemas universais.

Existem sim técnicas que fazem uso maior da quantificação e aquelas que confiam mais em registros não quantificados. Mas até essa diferença acaba sendo de grau e não absoluta, e casos intermediários abundam. Quando um pesquisador precisa fazer uma análise de conteúdo para categorizar as respostas a perguntas abertas em um questionário, chamaremos isso de uma técnica quantitativa ou qualitativa? O resultado final da categorização pode ser uma quantificação das frequências relativas, mas o processo envolve interpretação de conteúdos relativamente ambíguos em função do contexto. E, quando um observador participante fala sobre um consenso valorativo, numa comunidade que enfrenta a contestação de grupos minoritários, não estamos perante uma comparação de magnitudes (quantificação), apesar de não encontrarmos nenhum percentual?

Feliz ou infelizmente, número algum se interpreta a si mesmo. É preciso avaliar com cuidado qualquer tipo de evidência, quantitativa ou qualitativa, para poder inferir conclusões válidas. As diferenças entre técnicas preponderantemente quantitativas e qualitativas são basicamente de ênfase.

As pesquisas quantitativas privilegiam a tentativa de obter uma mensuração precisa, que permita comparar a frequência dos fenômenos. As qualitativas, por sua vez, pretendem obter uma compreensão mais pro- 
funda do contexto e da visão dos próprios atores para poder interpretar a realidade. Mesmo quando o material empírico se resume a um único indivíduo ou instituição, como acontece nas histórias de vida ou nos estudos de caso, a ambição de generalizar a outros indivíduos, grupos ou situações é clara, pois sem ela estaríamos falando de história ou de literatura, não de ciência social. A abordagem profunda do individual é justamente uma chave de acesso ao grupo. Assim, o estudo da biografia de Mozart por parte de Norbert Elias (1995) nos permite entender a relação entre a arte, a burguesia e a nobreza do seu tempo, bem como o nascimento do artista como uma figura autônoma.

De fato, há uma interpenetração constante. As pesquisas quantitativas também dependem do contexto para interpretar seus resultados. Por outro lado, também é possível, como já foi explicado, explorar o sentido dos atores através de surveys.

Uma das vantagens da pesquisa quantitativa é que os procedimentos atingem maior grau de padronização e podem ser prontamente comunicados (tipo e tamanho da amostra, erro amostral, etc.) de forma que possam ser replicados ou contestados com maior facilidade. Em pesquisa qualitativa, o grau de padronização é menor e as estratégias de controle do viés, por exemplo, menos consolidadas. Entretanto, isto significa que o cuidado com o rigor e com os controles (por exemplo, através da busca de casos contrários à hipótese) deve ser inclusive superior ao que existe em pesquisas quantitativas, de forma a garantir a validade das conclusões. Howard Becker (1992) dedicou ingentes esforços a encontrar padrões de validade nos estudos qualitativos que fossem equivalentes, embora não idênticos, aos aplicados nas pesquisas quantitativas. O próprio Malinowski, em seu apelo para a sinceridade metodológica, isto é, à necessidade de oferecer ao leitor tanto os materiais empíricos quanto um relato do percurso da pesquisa, ecoa o mesmo tipo de preocupação. 
A escolha das técnicas a serem empregadas deve depender, em princípio, do tema da pesquisa e do contexto em que ela acontecerá, e não da biografia ou das inclinações do pesquisador. Nem todas as técnicas são adequadas para todos os projetos de pesquisa. É preciso conhecer as fortalezas e fraquezas de cada uma. Seria tão absurdo tentar entender as gangues juvenis urbanas que desenvolvem condutas ilegais através da aplicação de questionários de 10 minutos a uma amostra aleatória de seus membros quanto tentar predizer o resultado de uma eleição a partir de uma etnografia. Por isso, o pesquisador, idealmente, deve conhecer o máximo de técnicas possível, o que lhe permitirá escolher a que mais se ajuste ao seu propósito ou, melhor ainda, incorporar várias delas no mesmo projeto de pesquisa, uma estratégia conhecida como triangulação.

Com efeito, diversas pesquisas bem sucedidas utilizam técnicas eminentemente qualitativas em conjunto com outras quantitativas, por exemplo, conduzindo entrevistas ou grupos focais para preparar um questionário ou para ajudar a entender os resultados do survey. Em suma, ambas as abordagens podem ser consideradas complementares muito mais do que antagônicas, a despeito do esforço de alguns para enfatizar a dicotomia.

\section{Ensino da Metodologia das Ciências Sociais no Brasil}

Antes de abordar esta questão, é imperativo realizar algumas qualificações e ressalvas. Em primeiro lugar, as observações que se seguem, a modo de ensaio, são produto da minha experiência como professor de métodos nas ciências sociais em várias universidades brasileiras, desde 1997 até o momento atual. Não deixa de ser irônico o fato de que um trabalho como o atual, que defende uma abordagem essencialmente empírica da ciência social, esteja baseado não em uma pesquisa sistemática e planejada, mas apenas num conjunto de observações pessoais. Apesar de ser um professor 
de métodos que escreve sobre o seu ofício, nem sequer posso reclamar legitimamente a utilização da técnica clássica da 'observação participante', visto que a observação não foi planejada nem registrada, e carece do percurso tradicional entre naturalização e estranhamento.

Infelizmente, não disponho de dados sistemáticos para comprovar ou falsificar minhas afirmações, que, portanto, devem ser entendidas, sobretudo, como uma provocação para futuras reflexões e indagações. De fato, vale registrar aqui a necessidade de que esse tema seja abordado como legítimo objeto de pesquisa pela ciência social, através da coleta e análise de dados sistemáticos. Esta sorte de meta-pesquisa poderia esclarecer muitos pontos obscuros e ajudar a reorientar o ensino da matéria.

Em segundo lugar, embora eu me apreste a escrever sobre o Brasil, acredito que a descrição se aplica não apenas ao país, mas também a muitos outros contextos, particularmente na América Latina. Eu mesmo, como estudante na Espanha, já sofri vários dos problemas aqui desenhados.

Em terceiro lugar, a realidade que pretendo descrever não é estática e está mudando progressivamente. Talvez a minha descrição crítica seja mais aplicável aos cursos de graduação do que às pós-graduações. Mesmo assim, por razões analíticas e retóricas, vou construir um modelo simplificado e idealizado. O teste último do sucesso deste texto não é o grau em que se assemelha à realidade, mas a medida na qual pode induzir reflexão e, em última análise, mudança.

Uma vez colocadas essas ressalvas, passo a resumir o meu diagnóstico sobre o ensino de metodologia das ciências sociais no Brasil.

A primeira constatação é que as ciências sociais brasileiras privilegiam a teoria em detrimento da pesquisa, promovendo um conhecimento antes erudito do que técnico. Em muitas universidades, os departamentos de ciências sociais ainda estão atrelados a Centros de Filosofia ou de Letras, frisando a origem comum desses saberes e distanciando as ciências sociais 
de conteúdos considerados mais técnicos, como a economia, apesar de esta última poder ser considerada, plenamente, uma ciência social. De fato, o tipo ideal de cientista social erudito que parece ser promovido em alguns círculos, caracterizado pela sua habilidade para citar autores e sua brilhante oratória muito mais do que pela sua capacidade de fundamentar empiricamente suas afirmações, não parece muito distante do estilo do ensino no direito ou na filosofia. É o argumento, e não o dado, que faz a diferença.

E, dentro da teoria, a primazia absoluta é conferida aos clássicos e à grande teoria social, mais do que a Teorias de Alcance Intermediário (Merton) ou microteorias apropriadas a campos concretos. Em sociologia, especificamente, a tríade Marx-Weber-Durkheim recebe uma atenção reverencial. Fazendo um paralelo cruel, e um tanto exagerado, é como se a física dedicasse boa parte do seu tempo a formar seus alunos nas teorias de Newton. Note-se, particularmente, que os clássicos não são abordados apenas como figuras inspiradoras ou pioneiras, mas como os portadores dos conteúdos centrais a serem aplicados e testados na realidade atual. Cabe argumentar que, se o Brasil precisa, com certeza, de dezenas ou talvez centenas de especialistas em Marx, Weber e Durkheim, o país requer centenas de milhares de profissionais que consigam formular, aplicar e avaliar políticas públicas. Estes especialistas necessitam, sem dúvida, de uma formação teórica sólida, mas também de ferramentas que lhes permitam responder às novas perguntas que a realidade formula a cada dia.

A predominância da teoria sobre a prática milita contra a importância outorgada ao ensino da metodologia. Em algumas universidades, o programa da disciplina de metodologia consiste em abordar como os clássicos (Marx, Weber e Durkheim) concebiam o papel do cientista social no seu tempo. Ou seja, oferecem-se, no máximo, elementos de epistemologia geral das ciências sociais, ao invés de ferramentas de pesquisa. Se em outros países podemos encontrar 'Departamentos de Métodos de Pesquisa', onde 
se ensinam esses métodos e se oferece conselho técnico aos pesquisadores dentro das faculdades de ciências sociais, isto é extremamente raro no Brasil. Para muitos dos meus colegas, a figura do metodólogo, ou seja, de um especialista em métodos que pode ajudar outros cientistas sociais em suas pesquisas, carece de sentido, visto que, na percepção deles, cada um desenvolve sua própria metodologia e, portanto, é o metodólogo de si mesmo. De acordo com este raciocínio, também não faria sentido contar com especialistas em teoria clássica, por exemplo, já que cada cientista social está obrigado a conhecer os clássicos. Entretanto, a figura do cientista social especializado em teoria clássica conclama muito maior legitimidade do que a do aspirante ao obscuro ofício de metodólogo.

Em vista desse relativo desinteresse em relação à pesquisa, não deve surpreender que haja graduados em ciências sociais, particularmente nos programas em que a monografia não é obrigatória, que se formem sem a capacidade de elaborar um projeto de pesquisa.

Outro exemplo de desvalorização da pesquisa é o configurado por estudos que contêm teoria e pesquisa empírica, entretanto completamente desatreladas uma da outra. Assim, são colocadas questões teóricas, seguidas por uma análise de dados que não aborda diretamente essas questões, e uma conclusão que confirma as teorias iniciais citando perifericamente os dados analisados. Quem já supervisionou monografias de alunos conhece muito bem o que estou descrevendo, mas é muito mais preocupante quando se trata de publicações acadêmicas. Um exemplo disto é o que Glaucio Soares (Cano; Soares, 2002) chamou de "Modelo FLACSO" de pesquisa na América Latina nos anos 60 e 70: uma introdução marxista precedia um conjunto de dados quantitativos ou qualitativos coroados por uma conclusão, também marxista, que prescindia dos dados analisados.

Há mais de 20 anos atrás, Fabio Wanderlei Reis (1991) já advertia, em relação à ciência política brasileira, contra os 'marcos teóricos' de 
feição ritualística e desligados dos problemas reais no trabalho de pesquisa. Paralelamente, Reis criticava, na mesma linha do apontado aqui, a predominância do "comentário erudito perenemente renovado dos clássicos da longa tradição de pensamento político" e a falta de treinamento metodológico dos profissionais da área.

Como já foi mencionado, a realidade é dinâmica e está em mutação. Acredito que o surgimento de graduações e pós-graduações em Políticas Públicas no país, com grande envolvimento de cientistas sociais, é um reflexo das limitações do modelo tradicional e da necessidade de mudanças. Contudo, a questão que se coloca é por que não foi possível abordar estas mudanças de dentro dos departamentos de ciências sociais e foi preciso criar novos diplomas. Assim, se por um lado essas novas graduações são um triunfo para os que pretendemos modificar o paradigma convencional, por outro acabam confirmando indiretamente a ideia de que um especialista em políticas públicas não é um cientista social.

A segunda grande constatação é que, na medida em que se dedica atenção à metodologia de pesquisa na formação das ciências sociais no Brasil, ela está voltada, avassaladoramente, para técnicas de pesquisa qualitativas em detrimento das quantitativas. Muito mais grave ainda é o fato de que, não raro, ambas são apresentadas em oposição, quando não em conflito aberto. Não estou me referindo apenas ao uso dos termos 'Método Quantitativo' e 'Método Qualitativo', que, como argumentei anteriormente, considero inadequados, mas à ideia de que ambas as estratégias de pesquisa se legitimariam pela mútua contraposição. Obviamente, esta guerra metodológica se salda, considerando a disparidade de forças, com a derrota dos 'quantitativos'.

$\mathrm{Na}$ visão contrária às técnicas quantitativas, elas seriam reificadoras, isto é, responsáveis por criar uma realidade artificial que deixaria de lado a subjetividade e o sentido da ação. Por outro lado, assinalam-se todos os 
possíveis vieses e erros atribuíveis às pesquisas quantitativas, especialmente todos os relacionados à tradução do fenômeno em um registro quantificável, sem mencionar que a grande maioria deles é, no mínimo, igualmente possível quando se usam técnicas qualitativas. O termo 'positivista' tornouse um verdadeiro xingamento metodológico para definir todas as opções metodológicas que se deseja condenar, com frequência sem explicar aos alunos em que consiste o positivismo clássico, muito menos sua contribuição ao nascimento da ciência social, nem o neopositivismo de começos do século XX. Como ninguém se define como positivista no momento atual, enfrenta-se um inimigo indefinido, mas não menos inquietante. Trata-se do velho truque retórico de construir, sob medida, um inimigo que se deseja derrubar, para destruí-lo depois à vontade. Obviamente, o inimigo não pode se defender pela simples razão de que não existe.

Pior ainda do que as críticas infundadas ou parciais é a impressão implícita de que quantitativo-qualitativo é um binômio antitético, perante o qual é preciso optar. Nos programas de pós-graduação em que são oferecidas as matérias de 'Métodos Quantitativos' e 'Métodos Qualitativos', é comum que os alunos tenham o direito de eleger apenas uma delas, escolhendo, assim, entre os dois extremos do abismo metodológico. Os exemplos de triangulação em pesquisa são raros e a noção de um antropólogo que ensina aos seus alunos o uso de surveys para estudar o parentesco, que pode ser encontrada em outros países, gera comoção no Brasil.

Estas pregações caem nos ouvidos férteis de muitos alunos, lastrados por um deficiente ensino da matemática e confiantes em que a tradição filosófica das ciências sociais possa evitar que eles precisem enfrentar o seu pavor da estatística.

Na versão mais delirante do "anti-positivismo" militante, a opção metodológica adquire matizes ideológicos, de forma que os pesquisadores qualitativos seriam necessariamente mais sensíveis às minorias (étnicas ou 
de gênero), mais libertadores e mais progressistas. As pesquisas quantitativas, por algum motivo, não apenas resultariam numa abordagem artificial da realidade social, mas também seriam identificadas com posições politicamente conservadoras e inclusive opressoras. Curiosamente, Marx leu atentamente o trabalho de David Ricardo, Adam Smith e toda a teoria econômica disponível na época antes de formular suas ideias. Inclusive, Marx elaborou um questionário para que este fosse respondido por uma amostra de operários, com o objetivo de elaborar um diagnóstico sobre as condições de trabalho dos trabalhadores na França. O questionário, do qual foram impressas 25.000 cópias, continha exatamente 100 perguntas abertas e foi publicado na Revue Socialiste de 1880 (Marx, 1880; ver Thiollent, 1982). Entretanto, alguns dos herdeiros distantes do velho Marx não se dão ao trabalho de estudar coisa alguma que esteja contaminada por números.

Se eu fosse revisar meu caderno de campo inexistente, relativo aos últimos 15 anos como professor de métodos, poderia mencionar algumas passagens reveladoras, como colegas irritados com o fato de os alunos usarem a noção de 'variáveis' em sala de aula, ou professores universitários falando contra o 'imperialismo' a propósito da iniciativa do chefe de departamento de sociologia de uma universidade federal de contratar um professor de técnicas quantitativas.

O resultado desta configuração é que muitos alunos formados em ciências sociais apresentam sérias dificuldades, não já em entender um modelo de equações estruturais, mas simplesmente em elaborar ou até interpretar uma simples tabela com percentagens. Igualmente pernicioso seria formar alunos que rejeitassem as etnografias ou não soubessem conduzir uma entrevista, mas isto é menos frequente.

De fato, em outras ciências (caso dos behavioristas na psicologia de meados do século XX), em outras latitudes e em outros momentos da ciência social houve exemplos de abordagens quantitativas igualmente 
intolerantes, que desconsideravam as pesquisas qualitativas como subjetivas e anticientíficas, e que não admitiam como científico nada que não pudesse ser mensurado externa e quantitativamente. Não conheço, entretanto, nenhum cientista social brasileiro atual que defenda esta posição. Por isso, o Judas positivista malhado pelos inimigos do quantitativismo foi criado como um espantalho, para que os alunos não tenham sequer a opção de conhecer aquilo que devem a priori desprezar.

Por sua vez, as técnicas de pesquisa qualitativa são ensinadas muitas vezes de forma impressionista. Usa-se comumente o termo "arte" para definir a pesquisa qualitativa. A ideia de arte poderia ser interpretada apenas como uma metáfora que destaca a criatividade. Porém, é comum identificar arte como um empreendimento submetido a critérios subjetivos para o qual não existe validação objetiva possível. Ou seja, como uma esfera oposta à da ciência. Se um objeto é artístico ou belo, isto depende da percepção da audiência, mas a validade de uma teoria não pode ser decidida pelo olhar do receptor, sob o risco de acabar no relativismo absoluto e decretar a morte da ciência. Este tipo de abordagens milita contra o rigor no ensino e na aplicação das técnicas qualitativas de pesquisa.

Em suma, a incúria da metodologia de pesquisa nas ciências sociais brasileiras acaba provocando uma severa restrição metodológica nos alunos, obrigados a contar com um arsenal metodológico limitado e a recorrer a uma ou poucas técnicas de pesquisa de forma sistemática. Nessa mesma medida, eles e elas precisam ou restringir os temas estudados ou aplicar a técnica que conhecem a temas ou contextos para os quais ela não é propriamente adequada.

Enquanto os cientistas sociais se autolimitam deliberadamente, o espaço é ocupado por economistas, por engenheiros ou arquitetos em temas urbanos, por epidemiologistas em temas de saúde e por outros profissionais com menos preconceitos metodológicos. 
Nenhum dos clássicos ritualmente citados nas salas de aulas das ciências sociais brasileiras manifestou tais restrições nas suas abordagens metodológicas. Quem sabe não está na hora de se voltar aos clássicos.

\section{Referências}

1. BECKER, H. Métodos de Pesquisa em Ciências Sociais. São Paulo: Hucitec, 1992.

2. CANO, I.; SOARES, G. D. As teorias sobre as causas da criminalidade. Rio de Janeiro: IPEA, 2002. Mimeo.

3. ELIAS, N. Mozart: sociologia de um gênio. Rio de Janeiro: Jorge Zahar Editor, 1995.

4. GIGERENZER, G. The Superego, the Ego and the Id in Statistical Reasoning. In: KEREN, G.; LEWIS, C. (Eds.) A Handbook for Data Analysis in the Behavioral Sciences: Methodological Issues. New Jersey: Lawrence Erlbaum Associates, 1993.

5. IBN KHALDUN. Introducción a la Historia Universal (AI Muqaddimah). México: Fondo de Cultura Económica, 1977.

6. INGLEHART R. et al. Human Beliefs and Values: a Cross-cultural Sourcebook based on the 1999-2002 Value Surveys. Mexico City: Siglo XXI Editores, 2004.

7. KAPLAN, A. The Conduct of Inquiry: Methodology for Behavioral Science. San Francisco: Chandler Publishing Company, 1964.

8. KUHN, T. The Structure of Scientific Revolutions. Chicago: The University of Chicago Press, 1962.

9. LINCOLN, Y. S.; GUBA, E. G. Naturalistic Inquiry. Newbury Park, CA: Sage, 1985.

10. LIPPMANN, W. Public Opinion. Nova York: Harcourt, Brace and Company, 1922.

11.MARX, K. Enquête Ouvrière. Revue Socialiste, n4, 20 avril 1880.

12. REIS, F. W. O Tabelão e a Lupa: teoria, método generalizante e ideografia no contexto brasileiro. Revista Brasileira de Ciências Sociais, v. 16, n. 6, julho, 1991. 
13. RITZER, G. Sociology: A Multiple Paradigm Science. Boston, MA: Allyn \& Bacon, 1975.

14. SCHWARTZ, S. H. The Universal Content and Structure of Values: Theoretical Advances and Empirical Tests in 19 countries. Jerusalem: The Hebrew University, 1990.

15. THIOLLENT, M. J. M. Crítica metodológica, investigação social e enquete operária. São Paulo: Polis, 1982.

16. VON WRIGHT, G. H. Explanation and Understanding. Nova York: Cornell University Press, 1971.

17. WEBER, M. A Objetividade do Conhecimento nas Ciências Sociais. In: COHN, G. (Org.) Sociologia. São Paulo: Editora Ática, 1979. (Coleção Grandes Cientistas Sociais. v. 13.).

Recebido em: 16/04/2012

Aceite final: 04/07/2012 